\title{
Erratum: Banking on cord blood from India
}

Jayaraman Killugudi

Nat. Biotechnol. 23, 1033 (2005)

In the print version of this article and the version originally published online, there is an error in the box on page 1033, paragraph 1, line 1. It read "Histostem, the South Korean biotech company...." It should have read "the Los Angeles-based Histostem Inc." The latter company is expanding into India, not the firm's affiliate, Korea-based Histostem Corp. Histostem Inc. acquired the territorial right to use the Korean company's technology in the Americas, Europe, Russia, India and Taiwan. The error has been corrected in the PDF version of the article. This correction is appended

to the PDF version.

\section{Erratum: Korean biotechs seize opportunity to list on public markets}

Sabine Louët

Nat. Biotechnol. 23, 1189-1190 (2005)

In the print version of this article and the version originally published online, a company name was misspelled. On page 1190, Box 1, paragraph 1, line 3, "Macrogene" should have been "Macrogen." This correction is appended to the PDF version.

\section{Erratum: Pessimistic response to FDA leadership change}

Jim Kling

Nat. Biotechnol. 23, 1325 (2005)

In the print version of this article and the version originally published online, a name was misspelled. On page 1325, paragraph 3, line 4; paragraph 4, line 1, 12; and paragraph 9, line 1, the surname of Kenneth Kaitin, director of the Tufts Center for the Study of Drug Development in Boston, has been misspelled. It should have read 'Kaitin' instead of 'Caitin.' This correction is appended to the PDF version.

\section{Erratum: China's biotech experiments}

Hepeng Jia

Nat. Biotechnol. 23, 1471-1472 (2005)

In the print version of this article and the version originally published online, the person in the photo on page 1471 was misidentified. The caption should have read "Zailin Yu, president of Beijing-based Bioway-Fortune Research Center for Gene Drugs, received financial support from a South 201 Korean venture capital group. Most Chinese biotech entrepreneurs are not as fortunate.” This correction is appended to the PDF version.

\section{Corrigendum: Multivalent avimer proteins evolved by exon shuffling of a family of human receptor domains}

Joshua Silverman, Qiang Lu, Alice Bakker, Wayne To, Amy Duguay, Ben M Alba, Richard Smith, Alberto Rivas, Peng Li, Hon Le, Erik Whitehorn, Kevin W Moore, Candace Swimmer, Victor Perlroth, Martin Vogt, Joost Kolkman \& Willem Pim C Stemmer Nat. Biotechnol. 23, 1556-1561 (2005)

In the print version of this article and the version originally published online, the second author's name was spelled incorrectly. The second author is Q Liu, not Q Lu as originally indicated. This correction is appended to the PDF version. 